\title{
Aspectos dos vínculos de sentidos do consumo alimentar em São Paulo: difusão publicitária e megatendências*
}

\author{
Eneus Trindade** \\ Clotilde Perez****
}

\section{Resumo}

Este artigo apresenta os resultados da pesquisa A produção de sentido na recepção da publicidade e nas práticas de consumo de alimentos na cidade de São Paulo. O objetivo do estudo foi analisar os tipos de vínculos de sentidos entre as práticas de recepção publicitária e práticas de consumo de alimentos no contexto da cidade de São Paulo, tanto no âmbito doméstico, a partir de três famílias observadas, quanto da realidade do consumo alimentar em ambientes públicos, tendo como critério comum às duas instâncias em comparação, a produção de sentido que as constituem como tipologias sígnicas desses vínculos, concebida a partir de metodologia interdisciplinar semio-discursiva e antropológica. Os resultados são reveladores de vinculações das mega-tendências junto às marcas e ao sistema publicitário de produtos e serviços de alimentos.

Palavras chave: Recepção. Publicidade. Práticas de consumo. Vínculos de sentidos. Alimentos.

\footnotetext{
* Trabalho resultado de pesquisa financiada pelo CNPq e baseado no texto apresentado junto ao Grupo de Trabalho Recepção: processos de interpretação, uso e consumo midiáticos do XXI Encontro da Compós, na Universidade Federal de Juiz de Fora, Minas Gerais, de 12 a 15 de junho de 2012.

** Professor doutor do Programa de Pós-Graduação em Ciências da Comunicação, Escola de Comunicações e Artes da Universidade de São Paulo, São Paulo-SP, Brasil. E-mail: eneustrindade@usp.br

*** Professora doutora do Programa de Pós-Graduação em Ciências da Comunicação, Escola de Comunicações e Artes da Universidade de São Paulo, São Paulo-SP, Brasil. E-mail: cloperez@terra.com.br
} 


\section{Links senses Aspects in food consumption in Sao Paulo: advertising difusion and megatrends}

\section{Abstract}

This paper presents the results about the research The production of meaning in reception advertising practices and food consumption in Sao Paulo city. The aim of the study was to analyze the types of links of senses between reception practices and advertising practices of food consumption in the context of Sao Paulo city, both domestically, from three families observed, as the reality of food consumption in public places, with the common criterion in comparison to the two instances, the production of meaning that constitute types of signs such as links senses, designed from interdisciplinary methodology semio-discursive and anthropological. The results are revealing connections with megatrends expressed in brands and advertising system of food products and services.

Keywords: Reception. Advertising. Consumption Practices. Links of senses. Food.

\section{Aspectos Vínculos de sentidos del consumo alimentário en Sao Paulo: difusiónpublicitaria y megatrends}

\section{Resumen}

El trabajo presenta los resultados del estudio La producción de sentido en las prácticas publicitarias de recepción y consumo de alimentos en la ciudad de Sao Paulo. El objetivo del estudio fue analizar los tipos de vínculos de sentidos entre las prácticas de recepción y las prácticas publicitarias de consumo de alimentos en el contexto de la ciudad de São Paulo, tanto a nivel doméstico, pertenecientes a tres familias observadas, como en la realidad del consumo de alimentos en lugares públicos, con el criterio común entre los contextos la búsqueda de la producción de sentido que constituyen tipos vínculos de sentidos, a partir de la metodología interdisciplinaria semio-discursiva e antropológica. Los resultados son reveladores de vinculaciones entre mega tendencias y las marcas, el sistema de la publicidad de los productos alimenticios y sus servicios.

Palabras clave: Recepción. Publicidad. Prácticas de consumo. Vínculos de sentidos. Alimentación.

\section{Introdução}

pesquisa A produção de sentido na recepção da publicidade
e nas práticas de consumo de alimentos na cidade de São
Paulo buscou analisar os tipos de vínculos entre as práticas de recepção publicitária e práticas de consumo de alimentos no contexto da cidade de São Paulo, tanto no âmbito doméstico, 
a partir de três famílias observadas de estratos sociais distintos ${ }^{1}$ (etnografia do consumo e análise crítica do discurso), quanto da realidade do consumo alimentar em ambientes públicos da cidade (fotoetnografia). $\bigcirc$ critério comum às duas instâncias em comparação foi a produção de sentido que as constituem como tipologias sígnicas desses vínculos, a partir de metodologia interdisciplinar semio-discursiva e antropológica.

Tal metodologia foi bastante explorada em outras oportunidades como (TRINDADE e MOREIRA, 2010; TRINDADE, 2011; TRINDADE, LLANO LINARES e BRAHIM, 2011), não sendo nosso objetivo aqui retomar essas discussões. Trataremos sim, de mostrar como a combinação de métodos e procedimentos etnográficos, fotoetnográficos (ACHUTTI, 2004), de estudos das mediações (MARTÍN-BARBERO, 2001 e CANCLINI, 2006) e da análise do discurso crítica inglesa (FAIRCLOUGH, 2001) empregados na pesquisa serviram de base ao trabalho reflexivo em comunicação para conceber os vínculos de sentidos entre marcas, publicidade e práticas de consumo dentro de uma dimensão dos processos de interação, seus fluxos e suas lógicas na construção dos sentidos do consumo alimentar, adaptando princípios de Braga (2006), a partir do conceito de midiatização e também da noção de meeting points ou pontos de contato trabalhado por Di Nallo (1999) sobre os vínculos entre marcas, publicidade e práticas de consumo, vividos nas situações de consumo e seus rituais, nos ambientes públicos e privados investigados, a partir de um conjunto de tendências de consumo hegemônicas do setor alimentar.

Nesse sentido, buscamos selecionar para este artigo argumentos que nos permitam discutir aspectos analíticos dos resultados finais da pesquisa em três eixos teóricos:

a) Sobre os vínculos de sentidos sígnico-materiais e simbólicos nos dois contextos como apresentamos em Trindade (2009), entendendo o primeiro tipo de vínculo como

\footnotetext{
${ }^{1}$ Essa exploração de três famílias distintas em níveis sociais, visou conhecer diferenças entre elas, não se pretende à generalizações, mas sim afirmações que se pautam sobre as realidades investigadas. Cabe destacar que a escolha das famílias seguiu critérios da ABEP-Associação Brasileira das Empresas de Pesquisa de Mercado, conforme dados apresentados em Trindade e Moreira (2010).
} 
referente à marca/produto com seu mundo da publicidade que torna-se o elo comum ou cronotópico entre o tempo e o espaço da marca e o tempo e o espaço dos consumidores-receptores. Cabe entender que na atualidade nossa acepção de recepção publicitária está expandida e inclui, sobretudo, a presença de produtos e suas marcas com lugar de manifestação do sistema publicitário na vida e no contato com as pessoas. Isto é, nas lógicas de processos das midiatizações das marcas ou do consumo midiatizado pelas marcas, o que nos faz perceber a marca como mídia. Neste caso, do consumo midiatizado pela marca, percebemos que ele se opera por uma influência direta e indireta das mensagens publicitárias e das demais expressões marcárias. Direta, pois os valores da publicidade geram identificação com o consumidor-receptor. Indireta, porque isso também depende de outros fatores ligados ao nível socioeconômico do sujeito, do seu repertório cultural e seus valores - que influenciam suas decisões de compra. O segundo vínculo, o sígnico-simbólico se refere a algum tipo de influência da publicidade, que não se reverte no consumo de um bem específico, mas que implica na incorporação de um estilo de vida, de um modo de existência pragmática ou afetiva que o consumidor-receptor adota em seus comportamentos de consumo e que toma para si como forma de manifestação de seus hábitos, o que por sua vez reforça seus valores e visões de mundo. Isso, logicamente, ganha adaptações e variações conforme repertório cultural e nível socioeconômico dos sujeitos.

b) O segundo aspecto teórico refere-se às lógicas de interação no processo de midiatização das marcas em seus rituais de consumo nas práticas sugeridas em mensagens e nas suas manifestações ritualísticas do cotidiano que foram amplamente discutidos em (LLANO LINARES, 2010), entendendo tais rituais como práticas que se revelam no caso da alimentação por rituais de compra, 
sugeridos pelas comunicações das marcas em suas mensagens de publicidade, bem como dos usos alimentares no preparo das refeições e apresentações dos pratos, dos momentos de celebração, assim como dos rituais que qualificam status e estados afetivos atribuídos aos alimentos. Tais rituais, por sua vez, foram determinados a partir da proposta de McCracken (2003, p.99-101), originalmente aplicados ao consumo de moda. Este antropólogo americano percebe o consumo demarcado por processos de transferências de significados do mundo socialmente construído para bens e dos bens para o consumidor, por meio de um sistema publicitário, em seu sentido mais amplo incluindo todas as expressões de difusão das marcas, e que define em linhas gerais a sugestão de práticas ritualísticas de compra, uso e posse.

c) E como último aspecto teórico, identificamos as perspectivas das produções de sentidos como esboçamos em Perez e Trindade (2011), a partir da tipologia dos vínculos identificados, frente às tendências de consumo alimentar detectadas no relatório (MADI; PRADO; REGO, 2010), sobre as megatendências mundiais e brasileiras no setor alimentar.

A partir dos dados de pesquisa e discussões dos textos citados, foi possível destacar algumas manifestações que por meio da observação implicada e do registro fotoetnográfico evidenciaram-se pela força da recorrência. São elas, o consumo "on the go", o consumo fast, o consumo hedônico e o consumo relacional.

O primeiro refere-se a um ponto de contato de alimentos práticos, prontos, embalagens miniaturizadas para o consumo, no contexto de trânsito e mobilidade que não é apenas tecnológica, mas que também se refere ao consumo alimentar. Já o consumo fast é decorrente desse movimento, pois além da mobilidade manifestada no consumo on the go expressa na materialidade do consumo de alimentos simultâneo ao deslocamento no espaço, outra manifestação associada ao tempo é o estímulo à rapidez. Essa rapidez, aqui intitulada fast, surge tanto nos processos de preparo dos alimentos, 
quanto na escolha (alimentos fáceis de serem ingeridos) e nas condições gerais de ingestão desses alimentos. Comidas semi-prontas, alimentação em pé, alimentação encostado em balcões, alimentação nas calçadas. Todo o contexto de aceleração impulsiona e pressiona a vida, o que inclui a alimentação. Há ainda o consumo hedonístico, que se revela nas manifestações que exaltam relações diversas de prazer com o consumo alimentar. E dessas sensações e experiências, percebemos que o consumo nos espaços privados e públicos, hoje mais os públicos, também manifestam a busca pelo prazer do convívio, do encontro, da troca, da descontração, a relação. Esses momentos revelam a dimensão relacional e social que a alimentação nas ruas e nas casas pode assumir. Compartilhar o momento da refeição é um signo de afetividade, cordialidade e até de cumplicidade. Almoço e jantar transformam-se em desculpa para o encontro, tanto em ocasiões mais formais, como os tradicionais almoços de negócios, mas também para descontração e evasão e gozo social. Esses momentos reúnem o prazer sensorial do alimento com o prazer do encontro e podem se transformar em uma privilegiada manifestação do encontro da satisfação humana. (PEREZ; TRINDADE, 2011, p.8-11).

Com este breve quadro, podemos seguir com a nossa interpretação sobre os vínculos de sentidos identificados na pesquisa.

\section{Sobre os resultados dos vínculos de sentidos e rituais alimentares}

No que se refere aos vínculos de sentidos, percebemos nos ambientes domésticos a força dos vínculos sígnicos-simbólicos na família de renda alta em seus rituais de compra, uso e posse, pela escolha de marcas presentes na mídia massiva, nas escolhas por espaços de compras referentes aos signos de distinção social e exclusividade, característicos da classe.

Este aspecto ganha nuanças distintas nas famílias de renda média e baixa, que optam, por questões socioeconômicas, por um consumo de marcas próprias e por locais de compra mais populares ou grandes varejistas como o Carrefour, o Walmart e outros. Predominam aqui os vínculos sígnico-materiais, embora sejam 
registrados vínculos sígnico-simbólicos que remetem à tradição alimentar e rituais de celebração entre as famílias, caso do consumo preferencial das famílias pelo panetone da marca Bauducco, mais consumido no Natal (família de renda baixa e alta) e da sobremesa preparada com leite condensado (Moça da marca Nestlé) pela mãe da família de renda média. Essas duas famílias mostram-se menos suscetíveis à midiatização do consumo alimentar das marcas, apesar de manifestarem algumas preferências, que nem sempre fazem parte do cotidiano de consumo e que são substituídas por outras mais baratas. Por outro lado, ambas mostram-se mais suscetíveis à midiatização publicitária promocional, visando à economia em seus rituais de compra. Criando lógicas de referência pautadas no sentido de gerar práticas econômicas do consumo material alimentar, manifestadas em rituais de compra. Tal aspecto aponta para exemplos distintos dos modos de presença do sistema publicitário na organização dos rituais de consumo entre os sujeitos investigados, isto é, modos de interação da publicidade configuradores de gradientes de vínculos: a presença midiatizadora da marca na vida constituindo os rituais de posse e uso e a comunicação promocional de varejo, modalizando os rituais de compra.

Ainda nos rituais de uso, percebemos nas três famílias a erosão das refeições em conjunto entre os membros, fato este que passa a ocorrer em momentos de confraternização, nos finais de semana, e em alguns casos durante o jantar, o que implica diretamente na migração do ritual alimentar doméstico para o ambiente público como iremos ver mais à frente.

Cabe destacar também no ritual de compra, o sentido de acúmulo presente na família de baixa renda, que está mais condicionado por sua situação socioeconômica do que por um efeito da midiatização publicitária das marcas de alimentos, isto é, demarcando no consumo as lógicas estratégicas de aproveitamento dos rendimentos familiares e de sobrevivência/existência, em acordo com o universo de preocupações desta classe social.

Na produção de sentido, percebemos pelos discursos das famílias e pelas imagens dos produtos, signos que fazem as distinções de classes. A família de alta renda se coloca espelhada com os 
valores da publicidade, trazendo para seu cotidiano os sentidos das marcas de alimentos, nem sempre coerentes com as práticas sociais alimentares pretendidas de saudabilidade, sobretudo, no que diz respeito à alimentação saudável. A alimentação é vista sob o prisma do prazer, permitindo a manifestação da figura masculina como cozinheiro (caso do chefe desta família de alta renda) e seu consumo alimentar é ocasionado por vínculos de sentidos de situações de consumo mais hedonísticas.

A família de renda alta não manifesta questionamentos sobre a publicidade de alimentos. Há um desalinhamento entre as práticas discursivas e práticas sociais pretendidas, manifestada em discursos ideais que, na maioria das vezes, não se revelam como ações de fato na vida cotidiana. A publicidade é percebida como um texto informativo sobre as novidades, o que conota uma forma de mascarar o poder sedutor e persuasivo das marcas no contexto dessa família. Há também o uso da publicidade como componente decorativo do lar pelo registro da campanha antiga de Coca-cola na parede da casa, fato este que não se observou nas outras residências.

A família de renda média usa também a publicidade como informação, sobretudo, para orientar os rituais de compra. Os vínculos sígnicos são mais materiais e talvez o vínculo sígnico- simbólico se manifeste em outros consumos da vida material, como também acontece na família de renda baixa. Todavia, a família de renda média apresenta um discurso de conformação com ausência de questionamentos sobre a publicidade de alimentos e manifesta ideologicamente o sentido da responsabilidade da mulher para a prática social alimentar da família na compra e preparo da comida, que é inclusive reproduzido pela publicidade, como no exemplo do leite condensado Moça.

Já a família de renda baixa mostra-se mais preocupada em seu discurso em tentar levar uma prática de consumo alimentar saudável (embora saibamos que a validação desta perspectiva demande outro tipo de estudo nutricional, que não compreendeu o escopo desta pesquisa) e mostra-se crítica à publicidade e ao seu poder de sedução, confessando a dificuldade em resistir aos seus apelos. 
A midiatização dos sentidos das marcas e publicidade se mostra presente na vida das famílias, não necessariamente só vinculada às compras e percebemos, sobretudo, os vínculos afetivos de grandes marcas mais presentes na mídia como Nestlé, Coca-cola e com posicionamentos de mercado consolidados e incorporados às vidas das famílias, numa lógica de presença da marca midiatizada, que se traduz como uma manifestação do sistema publicitário na vida das pessoas.

Seguindo a mesma linha para os ambientes públicos, observamos nos cinco percursos fotoetnográficos (Centro antigo de São Paulo, Bairro da Liberdade, Av. Paulista, Centro, Bairro do Bixiga e Circuito do Luxo da Oscar Freire) a presença de grandes marcas de bebidas (refrigerantes e cervejas) compondo o visual urbano em bares e restaurantes, como é o caso da Coca-cola, Skol, Brahma, bem como se percebe a presença de marcas locais dos estabelecimentos de serviços alimentares (bares e restaurantes), em nomes (estrangeiros, de lugares, de pessoas, de famílias, motivados pela origem dos proprietários, arbitrários, ligados aos produtos alimentícios que vendem) que criam, no caso de estabelecimentos mais conhecidos e antigos, uma espécie de pertinência e pertencimento aos bairros, que pela oferta de serviços para o consumo alimentar e de compra de alimentos revelam parte da identidade de tais espaços da cidade, a exemplo do Mercado Municipal e dos mercadinhos da Liberdade, das Casas do Norte, das Cantinas do Bixiga, do Bar Brahma, da Lanchonete do Estadão, do restaurante Famíglia Mancini, do D.O.M, do Carlota, entre outros.

Esses espaços da cidade também se mostram estratificados por níveis socioeconômicos, em função dos preços que praticam, do ambiente que proporcionam e da distinção dos gostos, conforme discussões de Bourdieu (1988), pelo tipo de alimentos que comercializam. Portanto, também mediatizam suas marcas e criam vínculos sígnico-simbólicos e pontos de contatos significativos da cidade em sua oferta de serviços de alimentos e que se tornam serviços que constituem também a oferta turística de restauração da cidade demarcando diferenças nos rituais de posse, pelo poder de desfrutar os signos gastronômicos da cidade. 
Além da publicidade e do merchandising das marcas nos pontos de venda dos estabelecimentos de alimentação, convivem manifestações de publicização ${ }^{2}$ de seus produtos de formas artesanais, como a lousa de giz que informa os cardápios por meio de manuscritos, que se associam por contiguidade à questão artesanal do preparo dos alimentos e a humanização, ritual este que não foi muito observado, à exceção das comidas de ruas nas barracas da Liberdade e do Churrasco Grego Gostei no centro da cidade e que seguem a lógica do on the go e do fast.

Outros espaços comerciais de serviços alimentares de menos destaque, em relação às grandes marcas e da grande publicidade, mas fundamentais à vida cotidiana, cumprem a função ordinária da alimentação (comprar, preparar e servir refeições) e geram vínculos sígnicos-materiais e pontos de contato, sujeitos a estímulos de promoções que atraem os consumidores no seu fluxo ${ }^{3}$ diário e que criam oportunidades de consumo alimentar, demarcando motivações e pontos de contato caracterizadores de rituais de compra e usos alimentares, apontando para uma força midiática, não menos importante, que se opera em tais situações de consumo, isto é, os sentidos de oportunidade das promoções e ofertas na vida cotidiana revelam um aspecto decisivo nas ações de consumo de varejo.

Nesse sentido, os rituais de refeição (usos alimentares), muito mais presentes nos espaços públicos do que nos domésticos na atualidade (ao menos no que se refere aos registros desta pesquisa), revelam pelas imagens coletadas um sentido de fluxo, movimento, às vezes com locais para sentar, outros de pé (os de refeições rápidas), mas também encontramos espaços para o consumo da celebração da comida como os espaços gastronômicos dos grandes

\footnotetext{
${ }^{2}$ Em Casaqui (2011), o conceito de publicização é formulado para mostrar que os acontecimentos das ações de difusão do consumo na vida cotidiana, que midiatizam as marcas, extrapolam as dimensões dos formatos publicitários clássicos dados em anúncios ou comerciais.

${ }^{3}$ A palavra fluxo aqui é utilizada neste trabalho pautada na referência do trabalho de Piedras (2006) sobre os fluxos publicitários de recepção, configurando o modo das ambiências onde os sujeitos sociais estão mergulhados no cotidiano e submetidos às mensagens publicitárias, marcas, que aqui são vistas como momentos que geram pontos de contato.
} 
chefs da cidade e até do movimento slow food, que demandam maior tempo dos consumidores para o contato com o ritual alimentar, marcadamente constituído de vínculos sígnicos-simbólicos e pontos de contato, que favorecem as experiências com o paladar.

Outro fluxo percebido nos percursos refere-se ao aspecto inter e multicultural da alimentação, as influências étnicas, de países, que tornam São Paulo um contexto ímpar na cena do consumo alimentar mundial. Percebemos que o fluxo de sentido do ambiente comercial, de pessoas, ao longo da história se manifesta como um tradutor sintético das fusões culturais na vida alimentar. Em São Paulo, isso parece se tornar um traço definidor da identidade local, manifestando um conjunto de elementos que permitem identificar esta cidade no plano das produções de sentidos como um lugar de manifestações culturais híbridas como apontou Canclini (2006) e também de manifestações efervescentes de tendências no setor alimentício, que se beneficiam dessas estratégias de hibridização.

\section{Sobre os resultados dos vínculos de sentidos frente às tendências de consumo}

Nesse sentido, São Paulo contempla as manifestações de tendências do mercado mundial no setor alimentar que podem ser classificadas de acordo com o relatório das megatendências deste setor, que se subdivide em cinco grandes classificações: sensorialidade e prazer, saudabilidade e bem-estar, conveniência e praticidade, qualidade e confiabilidade, sustentabilidade e ética (MADI; PRADO; REGO, 2010, p.41).

Conforme o trabalho de Llano Linares (2012)

Essa classificação foi criada após a análise de nove relatórios de tendências de alimentos feitos por diferentes agentes ao redor do mundo, porém, feitos com metodologias e terminologias distintas, notando-se uma convergência entre as conclusões no que diz respeito às principais mudanças e tendências do setor de alimentos (LLANO LINARES, 2012, p.92).

autor ainda complementa, 
Devido ao fato de que as tendências alimentares manifestam-se de formas distintas entre os diferentes tipos de consumidores pelas diferenças nos seus backgrounds socioculturais, o Brasil tem hoje uma forte similitude com três das cinco tendências encontradas no mundo: conveniência e praticidade; confiabilidade e qualidade; sensorialidade e prazer. As tendências restantes, no Brasil, converteram-se em uma só, [até o momento], pois não estão plenamente consolidadas independentemente (LLANO LINARES, 2012, p.93).

No País, o engajamento em prol do social e do meio ambiente vinculados às práticas de consumo de alimentos já está presente, porém atrelado a questões de saudabilidade e bem-estar [...] A procura pela qualidade de vida revela-se, nesse segmento, como um ideal mais amplo, que inclui a sociedade e o meio ambiente (MADI; PRADO; REGO, 2010, p.41).

Ainda segundo Llano Linares (2012, p.92-107) e Madi, Prado e Rego (2010) essas megatendências podem ser descritas da seguinte forma:

- Sensorialidade e prazer: É representada em três situações específicas: no crescimento das taxas de consumo de alimentos com valor agregado; a exploração de uma alimentação sem julgamentos morais em um contexto moderno, pura indulgência (prazer sem culpa); e o crescente interesse e valorização da gastronomia (MADI; PRADO; REGO, 2010, p.73). Fatores como o aumento do nível educativo, nas possibilidades de acesso à informação e fontes culturais são atualmente representados no mercado por diferentes fenômenos. Entre outras microtendências que se inserem na Sensorialidade e Prazer, se encontram: a busca pela cozinha regional, terroir, o aumento de produtos gourmet e versões premium de produtos industriais existentes; produtos que motivam um consumo sem culpa por meio de atributos que ajudem na diminuição de elemento de alto teor calórico; produtos exóticos que valorizam as culturas transnacionais e que demonstram o caráter cosmopolita do mercado de alimentos; produtos desenvolvidos em associação com chefs famosos, entre outras possibilidades. 
- Conveniência e praticidade: A valorização do tempo como recurso limitado; o balanço entre atividades laborais, vida e interesses pessoais; a mudança nas estruturas familiares são alguns dos fatores que tem levado os mercados industriais a adotar esta tendência no desenvolvimento de novos produtos. É possível encontrar na indústria alimentar produtos ligados a este conceito, a disponibilidade constante não deve ser um obstáculo para se alimentar: "refeições prontas e semi-prontas, fácil preparo, embalagens miniaturizadas de fácil abertura, fechamento e possibilidade de descarte rápido, destaque para produtos para o preparo em forno de microondas, além de serviços e produtos de delivery" (MADI; PRADO; REGO, 2010, p. 43). Esta linha geral agrupa tendências que ressaltam o processo de individualização, o valor da escolha pessoal na criação de novos produtos e a evolução das embalagens e porções de apresentação da comida que indicam condições características da sociedade atual, encorajada nos valores da rapidez, simultaneidade e efemeridade. Estas inovações podem estar baseadas tanto na necessidade de conveniência no processo alimentar quanto na personalização da dieta e das fontes nutricionais de acordo com características como faixas etárias ou necessidades nutricionais específicas com o diabetes, portadores de intolerâncias alimentares entre outros aspectos. Duas grandes categorias de produtos representam as inovações dentro desta tendência: produtos para consumir fora do lar (baseado no conceito on the go, e popularizado inicialmente pelas lanchonetes de fast food norte-americanas) e produtos práticos para o preparo de refeições ou já prontos para serem levados e consumidos. Nestas categorias cabem também características como: embalagens de fácil abertura; produtos que eliminam utensílios para seu consumo ou preparo; personalização de consumo; multipacks; embalagens para delivery (MADI; PRADO; REGO, 2010, p.85). Vale à pena notar que, algumas destas microtendências conver- 
gem com as necessidades de "saudabilidade e bem-estar", gerando uma proliferação de produtos convenientes e com características nutricionais mais avançadas.

- Confiabilidade e qualidade: A abertura das redes de informação facilitou o conhecimento das diferentes práticas nas indústrias alimentares. Os consumidores informados e conscientes dos processos alimentares disponíveis demandam produtos seguros e de qualidade garantida, valorando dessa maneira os processos de qualidade certificados. Nessa linha de pensamento, produtos que apresentam garantias de origem, qualidade de processamento, certificados de sistemas de gestão, processo de gerenciamento de riscos e qualidade de ingredientes são bem avaliados nos padrões de consumo dos indivíduos presentes nestas tendências (MADI; PRADO; REGO, 2010, p.46). Essa tendência está ligada à ideia de Sustentabilidade e ética, pois as práticas sustentáveis e éticas são, normalmente, aquelas que incentivam o uso de certificados nas embalagens com o propósito de identificar e garantir a qualidade e confiabilidade dos produtos e que evidenciam práticas laborais e ambientais corretas em todo o processo. Um dos seus fenômenos mais representativos - em conexão com a sustentabilidade e ética - é o modelo orgânico de produção alimentar, por exemplo.

- Sustentabilidade e ética: Não só o modelo produtivo é um elemento motivador no consumo de produtos que façam sua parte na construção do modelo sustentável. Existe uma crescente preocupação, entre alguns consumidores, com a possibilidade de participar e auxiliar causas sociais (fairtrade) por meio do consumo de produtos alimentícios, em uma perspectiva político-ideológica:

Em relação à sustentabilidade ambiental, vários aspectos estão sendo valorizados nos produtos pelos consumidores de diversos países, tais como uma menor "pegada" de carbono (carbon footprint), baixo impacto ambiental, não estar associado a maltratos aos animais, ter rotulagem ambiental, ter embalagens recicláveis e recicladas etc. (MADI; PRADO; REGO, 2010, p.46). 
Esta tendência é mais ampla porque suas características abrangem outras dimensões da vida, pois vai além dos desejos particulares dos indivíduos valorizando aspectos como o consumo solidário, os impactos da produção e das fases do sistema alimentar sobre o meio ambiente, o bem-estar animal. Produtos e organizações vinculadas a causas sociais, embalagens recicláveis e recicladas, processos produtivos sustentáveis; todas estas são características do fenômeno "comer bem fazendo o bem".

- Saudabilidade e bem-estar: $O$ indivíduo moderno busca um estilo de vida mais saudável, com ampliação do conceito de bem-estar (PEREZ; SIQUEIRA, 2009). Isso se evidencia claramente no consumo alimentar. Fatores motivadores como o envelhecimento da população mundial, o incremento da renda e a possibilidade de melhorar os hábitos alimentares, as descobertas científicas e os avanços na pesquisa dietética, influenciam o fato de que o homem está disposto a fazer um esforço adicional para viver bem, sem se importar com sua faixa etária nem situação socioeconômica (MADI; PRADO; REGO, 2010, p.43).

Se pensarmos tais tendências como vínculos possíveis de serem sentidos no consumo, podemos extrair dos ambientes domésticos e públicos investigados as últimas considerações sobre uma tipologia dos vínculos sígnicos-simbólicos identificáveis entre os dados da pesquisa.

\section{Os vínculos de sentidos do consumo alimentar em ambientes domésticos}

- Sensorialidade e prazer: a família de alta renda foi a que mais manifestou identificação com esta tendência pelo consumo de produtos importados, por gostar de novos sabores e na preocupação com momentos da alimentação mais elaborados aos fins de semana. Nas famílias de renda média e baixa esta tendência não aparece fortemente, 
embora reconheçam que a alimentação certamente traz momentos de prazer para seus membros, eles não manifestam no seu consumo tal aspecto como a família de renda alta. Aqui percebemos uma lacuna para identificação em pesquisas futuras acerca da dimensão dos padrões de gostos e dos sentidos dos prazeres alimentares para os distintos grupos sociais e de como as marcas se beneficiam desse aspecto para seduzir seus consumidores.

- Saudabilidade, sustentabilidade, bem-estar e ética: Alguns produtos (light, diet, zero...) e também os funcionais encontrados na casa da família de alta renda e mesmo na de baixa renda, em menor proporção, apontam para a presença das características desta tendência na vida das famílias. Este traço só foi ausente na família de renda média. No geral, não há, entre as famílias estudadas, uma preocupação com a crítica ao sistema produtivo alimentar, isto é, "Comer bem, fazendo o bem". Isso pode sugerir que as famílias de renda média e baixa têm pouca consciência dos processos produtivos alimentares ou poucas condições financeiras para consumir produtos e marcas com as características desta tendência, normalmente mais caros. Abre-se aqui outra demanda de estudos interessantes para o trabalho sobre o consumo e mediatização alimentar na perspectiva destas tendências e seu amadurecimento e incorporação na sociedade brasileira.

- Conveniência e praticidade: Isso foi verificado mais nas famílias de alta renda e renda média. Na primeira família em uma das visitas realizadas, percebe-se a presença de uma embalagem de pizza sob o fogão e produtos enlatados nos armários de cozinha do apartamento. Na segunda família, onde existem adolescentes na casa, tem-se a presença de lanches, hamburguer congelado, nuggets, chikenitos e outros produtos semi-prontos que apontam para o consumo de alimentos nesta tendência. Não houve registros consideráveis que manifestam adesão a esta tendência na família de baixa renda. Aqui é onde encontramos uma 
grande variedade de estudos socioculturais da alimentação, sobretudo no que se refere "à mcdonaldização dos costumes" alimentares como já indicou Fladrin e Montanari (2001). Mas acreditamos que o assunto não está esgotado, sobretudo, no que se refere à qualidade dos vínculos de sentidos que podem ser desenvolvidos nesta temática.

- Qualidade e confiabilidade: apresenta-se em todas as famílias, com gradações distintas, todos querem o melhor e o que gostam para comer, dentro de suas posses. No entanto, não é notória a valorização de selos de qualidade, referências à origem, rastreamento de fornecedores e esclarecimentos sobre os ingredientes. Todavia, lançamos a questão sobre os sentidos de qualidade e confiabilidade para os vários estratos sociais, cabendo aqui aprofundamentos de pesquisas futuras nesta temática.

\section{Os vínculos de sentidos do consumo alimentar em ambientes públicos}

- Sensorialidade e prazer: o percurso da gastronomia de luxo, com os restaurantes dos Chefs, é o melhor exemplo disso, mas há experiências sensoriais, prazerosas, não só ligadas a este percurso. Ir ao Mercado Municipal de São Paulo, na festa da Achiropita, comer pizzas em lugares tradicionais, ir à Liberdade e comer o lanche de pernil do Estadão ou sanduíche de mortadela do Mercado, são experiências gastronômicas que fazem os sentidos da cidade e mostram que cada bairro tem seus sabores específicos. Isso mostra que tais marcas criam vínculos de sentidos que geram no consumidor-receptor do lugar uma lógica de identificação e pertencimento, como discutiu Sousa (2005). Além disso, assim como na dimensão alimentar doméstica, nos percebemos diante da possibilidade de estudos sobre os padrões de gostos, mas aqui direcionados às suas vinculações de sentidos e pontos de contato com os espaços alimentares da cidade e os rituais de consumo neles vividos. 
- Saudabilidade e sustentabilidade, bem-estar e ética: os percursos realizados e talvez o tipo de metodologia utilizada, a fotoetnografia, não permitiu a identificação desta tendência de modo significativo no fluxo cotidiano dos locais públicos pesquisados, exceto pelos registros de casas de sucos naturais e algumas opções ditas "naturais" e, portanto, mais saudáveis em tese. Mas isso acontece apenas no nível da manifestação dos promotores de tais consumos, não sendo possível verificar tal aspecto de fato. E nem era este o nosso objetivo do estudo fotoetnográfico realizado. Assim, como nas famílias observadas e como aponta o relatório que dá base a esta classificação, parece-nos ainda que a cidade de São Paulo e, por consequência, seus cidadãos (em sua maior parte), não estão totalmente engajados nos aspectos desta tendência. Isso aponta para uma falta de clareza na mentalidade das pessoas sobre tais conceitos, o que dificulta a assimilação simbólica no cotidiano de consumo, como prática social desejável. Contudo, sabe-se que existem lojas e espaços comerciais voltados à alimentação orgânica, preocupados com a origem e a produção da matéria-prima constituindo os serviços alimentares, a exemplo disso registramos que, nos trabalhos de fornecedores do restaurante D.O.M do Chef Alex Atala e do restaurante Brasil a Gosto da Chef Ana Luiza, existe esta preocupação. Em função desta primeira constatação de pesquisa, que não pode ser entendida como uma realidade absoluta, entende-se que o item abre um importante espaço para investigações específicas sobre o consumo e a midiatização de marcas e publicidades de alimentos nestas tendências.

- Conveniência e praticidade: nesta tendência o percurso da Avenida Paulista é mais representativo, embora seus aspectos tenham sido encontrados nos registros na festa da Achiropita e no bairro da Liberdade com vários produtos on the go, prontos para o consumo fast de pessoas em trânsito. 
- Qualidade e confiabilidade: como nos ambientes domésticos, percebemos que os ambientes públicos nos serviços alimentares também demandam a preocupação com esta tendência, até porque existe regulação, fiscalização e regulamentação para a atuação de estabelecimentos alimentares, que buscam garantir a confiabilidade minimamente esperada destes serviços. Mas este foi um aspecto que não foi registrado na pesquisa fotoetnográfica e que até poderia ter sido levantado, no caso, manifestar-se-ia por registros de certificados da vigilância sanitária expostos nas paredes dos estabelecimentos. Contudo, a maioria das fotos foi feita em ambientes externos e essa verificação demandaria uma pesquisa específica. Além disso, a questão da qualidade e confiabilidade abre significativos desdobramentos sobre a percepção de risco na alimentação em locais públicos, no que tange à percepção dos serviços alimentares prestados ao consumidor associada à imagem e credibilidade em comunicação passada pelas marcas dos estabelecimentos, que também são constitutivas de vínculos de sentidos e que aproximam esses espaços comerciais específicos da alimentação de seus consumidores na cidade de São Paulo.

\section{Considerações finais}

Percebemos, a partir do exposto, um conjunto grande de desdobramentos para futuras pesquisas. Tanto nos ambientes domésticos como nos públicos as tendências aparecem hibridizadas e em gradações, o que demanda o estudo pormenorizado dos vínculos de sentidos que as constituem e que possibilitam a identificação dos pontos de contatos como diria Di Nallo (1999), que dão origem as várias situações de consumo em seus rituais caso a caso.

Nossa intenção com esta pesquisa interdisciplinar de natureza antropológica e semiodiscursiva, dentro do critério de pertinência sobre a produção de sentido mediática nos contextos estudados, foi mostrar a visão do nosso grupo de pesquisa, esclarecendo que tal 
abordagem não esgota todas as possibilidades de vínculos de sentidos frente às tendências de consumo, mas sim demarcar um espaço que pode ser aprofundado e aprimorado em vários segmentos do consumo na construção de uma teoria dos vínculos de sentidos no seu aspecto mediatizador da vida do consumo material, aqui demonstrado no campo da midiatização do consumo alimentar.

\section{Referências}

ACHUTTI, L. A. Fotoetnografia. Porto Alegre: Ed. UFRGS/Tomo Editorial, 2004.

BRAGA, J. L. Sobre "mediatização" como processo interacional de referência. In Anais XV Encontro Nacional da Compós. Bauru: PPGCOM-UNESP/ Compós, 2006. p.1-16.Grupo de Trabalho comunicação e sociabilidade.

BOURDIEU,P. La distinción. Madrid: Taurus, 1988.

CANCLINI, N. G. Culturas híbridas. Estratégias para entrar e sair da modernidade. São Paulo: EDUSP. 1996.

CASAQUI, V. Por uma teoria da publicização: transformações no processo publicitário. Revista Significação. Revista de Cultura Audiovisual. São Paulo, PPGMPA-USP, n. 36, p. 131-151, 2011.

Di NALLO. E. Meeting points. Marketing para uma sociedade complexa. São Paulo: Cobra, 1999.

FAIRCLOUGH, N. Discurso e mudança social. Brasília: Ed. UNB, 2001

FLANDRIN, J-L; MONTANARI, M. (org.). História da alimentação. 2. Da Idade Média aos tempos actuais. Lisboa:Terramar, 2001.

LLANO LINARES, N. Transferência simbólica de significados no sistema alimentar. In: TRINDADE, E.; PEREZ, C. (Orgs.). I Pró-Pesq PP-Encontro Nacional de Pesquisadores em Publicidade e Propaganda. São Paulo: ECA/ USP. GT- Propaganda e Linguagens, 2010. Diponivél em www.eca.usp/propesq . Acesso em: 10 jan. 2011.

- A cultura material hoje: a influência das inovações de consumo do setor alimentar nas tendências retóricas publicitárias. 2012. Dissertação (Mestrado em Comunicação Social) - Escola de Comunicações e Artes, Universidade de São Paulo. 
MARTİN-BARBERO, J. Dos meios às mediações. Rio de Janeiro: Ed. UFRJ, 2001.

MADI, L.; PRADO, A.: C. REGO, R, A. Brasil food trends 2020. São Paulo: Ed. Fiesp-Ital, 2010. Disponível em: http://www.brasilfoodtrends.com.br/ Brasil_Food_Trends/index.html. Acesso em: 09 jan. 2011.

McCRACKEN, G. Cultura e consumo. Novas abordagens ao caráter simbólico dos bens e das atividades de consumo. Rio de Janeiro: Ed. Mauad. Trad. Fernanda Eugênio. 2003. Coleção Cultura e Consumo coordenada por Everardo Rocha.

PEREZ, C.; TRINDADE, E. Marcas e Publicidade de Alimentos: Vínculos de Sentidos no Consumo da Vida Doméstica e nos Ambientes Públicos de São Paulo. In Anais XXXIV Congresso Brasileiro de Ciências da Comunicação. Recife: UNICAP/ INTERCOM. set, 2011. p.1-17. NP- Publicidade e Propaganda.1 CD -Rom.

PEREZ, C.; SIQUEIRA, R. Observatório de Tendências: o uso da metodologia de bricolagem no estudo de tendências comportamentais e de consumo. In FREITAS, H; MARTENS, C.; ANDRIOTTI, F.; MUNIZ, R. (Orgs.). Quanti e quali. E-book de casos do quanti \& quali 2009... Canoas: Sphinx, 2009. Disponível em:

http://divaoliveiradotcom.files.wordpress.com/2012/03/artigo_v2.pdf Acesso em: 13 jan. 2011)

PIEDRAS, E, R. As práticas de recepção da publicidade como fluxo: apontamentos teórico-metodológicos. In JACKS, N; PIEDRAS, R. E; VILELA, R. (Orgs.). O que sabemos sobre as audiências. Porto Alegre. ALAIC Gt- Estudios de Recepción/Ed.Armazém Digital, 2006. p.69-72.

SOUSA, M. W. Recepção midiática: Linguagem de pertencimento. Revista Latinoamericana de Ciencias de La Comunicación. São Paulo, ALAIC/USP, jan-jun,v. 2 n.2. p. 10-21, 2005.

TRINDADE, E.; LLANO LINARES, N; BRAHIM, V. F. El consumo alimentario que marca el centro de São Paulo: una experiência fotoetnográfica del consumo y de la publicidad de alimentos. Revista Sphera Pública. Murcia, Universidad Católica de Murcia, v. 11. n.1, p. 331-349, 2011.

TRINDADE, E. Consumo alimentar familiar e publicidade: a recepção na perspectiva da ADC. In: Anais XX Encontro Anual da Compós, 2011, Porto Alegre. XX Encontro Anual da Compós. Porto Alegre : UFRGS/FABICO/ Compós, p. 1-15. 2011.1CD-Rom Grupo de Trabalho de Recepção: processos 
de interpretação, uso e consumo midiáticos.

TRINDADE, E.; MOREIRA, R. A. L. Aspectos da recepção publicitária e das práticas de consumo em três famílias paulistanas. Revista ECOPós. Rio de Janeiro, UFRJ, v. 13, n.1 p. 63-79, 2010. Disponível em: http://www.pos.eco. ufrj.br/ojs2.2.2/index.php?journal $=$ revista \&page $=$ article \&op $=$ view $\&$ path $\% 5 B$ \%

TRINDADE, E. Da etnografia à produção de sentido da recepção publicitária e das práticas de consumo na vida social. Animus- Revista Interamericana de Comunicação Midiática, v. 15, n.2. p. 1-15, 2009. Disponível em: < http:// w3.ufsm.br/animus/animus_2009-1_art07.html>. Acesso em: 15 fev. 2011.

\section{Eneus Trindade}

Coordenador do PPGCOM/USP, Livre-Docente em Comunicação pela ECA/ USP, Pós-doutor em Antropologia visual pela Universidade Aberta de Portugal, Doutor e Mestre em Ciências da Comunicação pela ECA/USP. Presidente da Associação Brasileira de Pesquisadores em Publicidade. Coordenador do Grupo de Estudos Semióticos em Comunicação, Cultura e Consumo-GESC3/ CNPq/USP.

\section{Clotilde Perez}

Livre-Docente em Comunicação pela ECA/USP, Pós-doutora em Comunicação pela Universidade de Múrcia-Espanha, Doutora em Comunicação e Semiótica pela PUC-SP e Mestre em Administração pela PUC-SP. Vice-Presidente da Associação Brasileira de Pesquisadores em Publicidade.Vice-Coordenadora do Grupo de Estudos Semióticos em Comunicação, cultura e Consumo-GESC3/ CNPq/USP. 